\title{
Accuracy and Stability of Numerical Algorithms
}

Higham, Nicholas J.

2002

MIMS EPrint: 2006.75

Manchester Institute for Mathematical Sciences

School of Mathematics

The University of Manchester

\footnotetext{
Reports available from: http://eprints.maths.manchester.ac.uk/

And by contacting: The MIMS Secretary

School of Mathematics

The University of Manchester

Manchester, M13 9PL, UK
} 


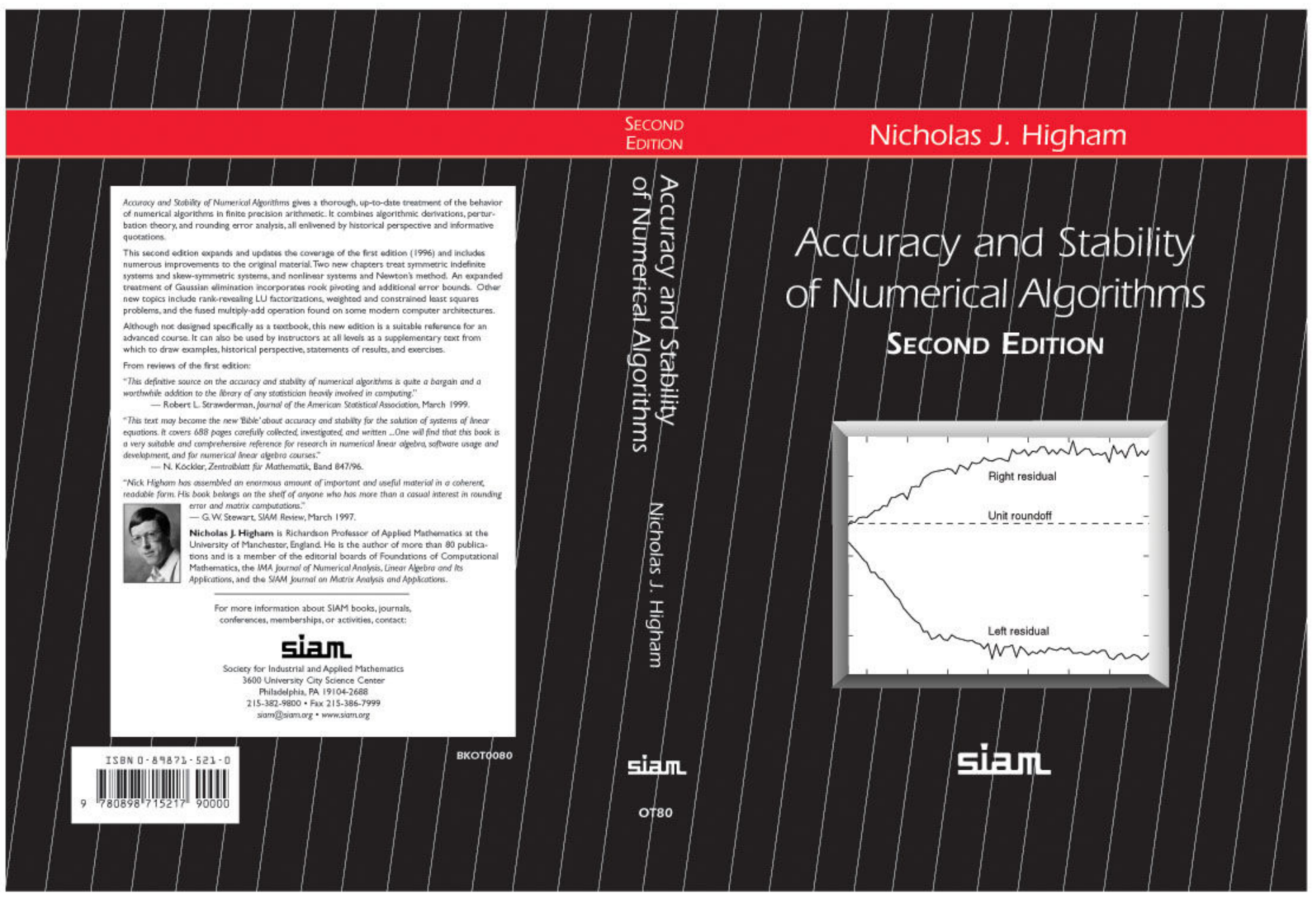

